\title{
Erratum to: Paediatric thyroid carcinoma in disguise: papillary thyroid carcinoma presenting with thyrotoxicosis and diffuse goiter
}

\author{
Tony H. T. Sung • Eric M. W. Man • Wendy W. C. Wong
}

Published online: 6 July 2012

(C) Springer-Verlag 2012

Erratum to: Pediatr Radiol (2012) 42:377-379

DOI 10.1007/s00247-011-2189-x

\begin{abstract}
Papillary thyroid carcinoma is rare in children. Its clinical manifestation may deviate from that observed in adult patients. We present a 14 -year-old girl with papillary thyroid carcinoma. We then discuss various distinctive sonographic signs that may aid diagnosis, and we discuss differences in clinical features between children and adults.
\end{abstract}

Keywords Thyroid carcinoma $\cdot$ Paediatrics $\cdot$ Thyrotoxicosis

The abstract and keywords of this case report were mistakenly deleted during typesetting. The missing material is presented here.

In addition, initials were added to the authors' names and their updated affiliation is presented below.

The online version of the original article can be found at http://dx.doi.org/ 10.1007/s00247-011-2189-x.

T. H. T. Sung $(\bowtie) \cdot$ E. M. W. Man · W. W. C. Wong

Department of Radiology,

Pamela Youde Nethersole Eastern Hospital,

3 Lok Man Road, Chai Wan,

Hong Kong, HK, People's Republic of China

e-mail: sht557@ha.org.hk 